\title{
How Do Anti-abortion and Abortion Rights Groups Deploy Ideas About Islamic in Their Activism Regarding Abortion
}

\author{
Zhixin $\operatorname{Jin}^{1}$ \\ ${ }^{1}$ Shanghai United International School, Shanghai, China \\ Correspondence: Zhixin Jin, Shanghai United International School, Shanghai, China. E-mail: \\ cindy_jinzx@hotmail.com
}

Received: October 29, 2018

Accepted: December 20, 2018 Online Published: February 28, 2019

doi:10.5539/jpl.v12n1p38

URL: https://doi.org/10.5539/jpl.v12n1p38

\begin{abstract}
Abortion is a hotly debated topic among Muslim communities, yet not many people outside of Muslim communities noticed this controversy, assuming that all Muslims hold similar opinions. In this paper I seek to answer the question: How do anti-abortion and abortion rights groups deploy ideas about Islam in their activism regarding abortion? I analysed the language those organizations use when describing Muslim communities and Muslim views, in order to learn their opinion. I found that a majority of those organizations did not include arguments from both sides, and almost all the Anti-Abortion Websites included generalizations of the Muslim community, and uses the Islamic Religion's conservative factors as their method to persuade more Muslim people to join their stance on abortion. My research can serve as a contribution to research on broader questions such as: Why do a significant amount of people worldwide have very monolithic and stereotypical impressions on the Islamic religion? How influential is religion to a country's justice system and social morals? Those are all relevant question that matters significantly to our world, I hope that my research can have an impact and perhaps inspire further research into these questions.
\end{abstract}

Keywords: Muslim, Islam, abortion, reproductive justice, social stereotypes

\section{Introduction}

\subsection{The Stereotype}

The subject of abortion has attracted increasing attention worldwide, often in relation to Catholicism. Many people do not realize that abortion is also a hotly debated topic in Muslim majority countries. Despite the homogenous and stereotypical representations of Muslim people in the media as politically conservative religious fundamentalists, there are significant differences among Muslim people and Muslim majority countries. This is nowhere more evident than in the diversity of Muslim positions on abortion. For example, the Muslim Public Affairs Council, an organization that describes itself as "a national public affairs nonprofit organization working to promote and strengthen American pluralism by increasing understanding and improving policies that impact American Muslims" (mpac.org), created a video entitled "Abortion - Islam: Questions You Were Always Afraid to Ask" (MPAC National, youtube.com). In it, the interviewer asks a religious leader, "Dr.H, what's the Islamic stance on abortion?" Dr. H responds, "Never say never... there is nothing called absolute never... it depends."

\subsection{The Truth}

Contrary to the ideas circulated by many anti-abortion activists and some abortion rights activists, there is no single Islamic stance on abortion. The Islamic religious body is comprised of 49 Muslim-majority countries, which make up $21 \%$ of the world's population (Desilver and Masci pewresearch.org). With that large of an Islamic population, there is bound to be diversity in opinions: the stance of every individual Muslim on many different issues inevitably differs from one another. And so, even though Muslims are united under one religion, there is no single stance that captures how all 1.6 billion Muslims feel on any single issue. Different Muslim countries encourage different interpretations of the Qur'an and shari'a. The shari'a is a product of articulations of legal discourses and institutions to varying patterns of society and politics and has therefore varied considerably over time and region (Zubaida 2003, p. 1). Among Muslims, there are four main approaches to abortion: abortion is allowed, abortion is allowed under certain circumstances, abortion is disapproved of, or abortion is forbidden 
(Hessini 76). There is a primary division among Muslims between Sunnis (75\%-90\% of Muslims worldwide), Shiites (10\%-20\%) and Schismatics (5\%-10\%) (Barret et al. 2001; CIA 2012); these three groups do not have a central authoritative structure or any single dominant school of theology (Brockopp 2003). Due to the division among Muslim religious views, and because "many Muslims incorporate their religion into almost every aspect of their lives" (Daar et al. 2008, p. 410), there have been many debates amongst Islamic scholars concerning the subject of abortion. As Donna Lee Bowen (an American political scientist who specializes in studies of family policy in the Middle East) writes, "Debate on this subject [abortion] is spirited and ongoing" (Bowen 179). Bowen cites the example of the 1994 Cairo Population Conference, where "the most hotly debated topic of the conference was abortion" (Bowen 160).

According to Gilla K Shapiro 's article "Abortion law in Muslim-majority countries: an overview of the Islamic discourse with policy implications," in 47 out of 49 Muslim majority countries, abortion is allowed with different requirements, and up to 10 of those countries (21.28\%) allow abortion on demand (Shapiro 490). This difference across the countries is mainly due to the different schools of interpretation of the religious text. A majority of Muslim countries consider abortion before 120 days (or four months) of pregnancy as acceptable, while after 120 days they consider abortion blameworthy and forbidden (according to the to the Qur'an after 120 days the fetus becomes a baby and has a soul). In 1971, an international conference on Islam and family planning concluded that "Islam forbids abortion after the fourth month of pregnancy unless the woman's life is in danger but allows for abortion under several circumstances in the first four months" (Hessini 2008, p.24).

In the article "Abortion, Islam, and the 1994 Cairo Population Conference," Donna Lee Bowen discusses one example of the debates between different Muslim groups: "Islamic activists utilized the Cairo Population Conference as a forum to put pressure on political leaders, religious leaders, and Muslims, in general, to prohibit abortion completely, while a few reformers, following the example of Tunisia, suggest that abortion in the early months of pregnancy should be allowed without condition" (Bowen 166). Bowen also states in the same article that ever since the start of the debate on the jurisprudence literature of the 9th century, ulama (a body of Muslim scholars who are recognized as having specialist knowledge of Islamic sacred law and theology) has not been able to agree on the point at which the fetus becomes "infused with life." Although they do agree that abortion, as an act of murdering a created soul, is forbidden, they cannot agree on when the act becomes abortion because the spirit has entered the fetus. Most anti-abortion activists, however, ignore the diversity of opinions on this issue among Muslims. For example, the website of an anti-abortion activist group the Society for the Protection of the Unborn Children (spuc.org) says the following of Islam in their "Religious View on Abortion" section: "Islam teaches that life begins at conception and is created by God. The unborn child has certain rights such as the right to care, protection and life. Abortion on any grounds is forbidden in the Islamic holy book Al'Quran. 'Do not kill or take a human life which God has declared to be sacred' (Chapter 6, verse 151)." This statement generalizes the view of the whole Islamic body under an inaccurate categorization and misinterprets the statements in the Qur'an. According to Gilla K Shapiro, it is accurate that the Quran condemns killing, and particularly infanticide out of economic hardship; however, these passages are generally understood to refer to live offspring, not abortion (Katz 2003). Shapiro also asserts, "the Quran is sensitive to a staged development between conception and childbirth, which has led to diverse perspectives of law depending on the gestational stage of the fetus (Musallam 1983)." Therefore, the SPUC website generalizes the whole Muslim religious body under a false interpretation of their religious text regarding abortion. The Islamic section on the website of a reproductive justice organization, the Religious Coalition for Reproductive Choice (rcrc.org) does a much better and more detailed analysis of the Qur'an; the detailedness of their analysis and explanations is an attempt to convince and persuade, which seems to naturally assume that the readers of the website page, Muslims, are conservative and anti-abortion. Although not stated directly on the website, the complexity of the language on RCRC, like the simplicity of the language on SPUC, generalizes the Muslim population to some extent.

\subsection{My Aim}

In this paper, I seek to answer the following question: How do anti-abortion and abortion rights groups deploy ideas about Islam in their activism regarding abortion? I argue that these groups use very different ways of presenting Islamic ideas on abortion to fit their own political stances. In order to prove my argument, I first draw from scholarly reviews of the prevalent perceptions of the issue of abortion among different Muslim communities in nMiddle eastern countries; I then outline the methods I am using for my study; and finally I examine the different websites of both supporters and opponents of abortion. 


\section{Relevant Scholarships}

\subsection{Leila Hessini}

Scholars who have written about Islam and abortion have tended to focus on the differences between Muslim-majority countries' policies and attitudes toward abortion. For example, in "Abortion and Islam: Policies and Practices in The Middle East and North Africa," Leila Hessini provides a general overview of the religious, legal, social, and medical factors that further or hinder women's rights, particularly rights surrounding abortion and reproductive justice, in the MENA (Middle East and North Africa) region. Hessini explains that, although the policies and attitudes toward reproductive rights differ greatly amongst those countries, religion is still the main factor that affects reproductive justice. One of the most important reasons for the different attitudes toward reproduction is that individuals are encouraged to read and analyze traditional Muslim religious texts on their own. There are four official schools of interpretation that exist in Sunni Islam, while Shiites have their own methods of jurisprudence and thought (Hessini 76). These schools have developed a significant amount of shari'a (Islamic law), which differs from country to country (Hessini 76). However, Hessini argues that there seems to be no apparent link between state religion, individual religiosity, and abortion prevalence. Iran, with one of the highest abortion prevalence rates in the region, is also ruled by some of the most conservative Muslim clerics (Hessini 82).

At the same time, unsafe abortions and pregnancies from rape have become increasingly recognized by Muslim religious leaders as legitimate reasons to legalize abortion and provide reproductive services. For example, "In Egypt, the Grand Mufti argued that rape victims should have access to abortions and to reconstructive hymen surgery to preserve female marriageability and virginity" (Hessini 78). However, these leaders still don't recognize abortion under normal circumstances as a female reproductive choice or right. Interestingly, fetal impairment seems to be a large motivator for allowing abortion. Furthermore, the laws in almost all the Muslim countries does state: "do not punish the man involved in the unwanted pregnancy unless he tries to perform the abortion himself" (Hessini 78). However, in some regions such as Kuwaiti, although there is a Fatwa (non-binding religious edict) that supports abortions to end pregnancies of rape, it has not been translated into a binding governmental law, which means that terminating pregnancies of rape is still illegal in this country despite being religiously supported. Many countries such as Syria value post-abortion care more than abortion itself, includes post-abortion care services as part of the national sexual and reproductive health program, while still restricting access to abortion. According to Hessini, the outlook on abortion in many of these countries has more in common with fundamentalist Christian values than with Islamic values; she argues that French colonial law has influenced abortion policy in Algeria, Iran, Lebanon, and Mauritania, where the punishment for killing a child who is already born is less than it is for terminating a pregnancy (Hessini 79).

\subsection{Gilla K Shapiro}

Leila Hessinis's writing about the diversity of opinions on abortion in Muslim countries focuses ono a political point of view; other scholars have focused on these issues through different lenses. Gilla K Shapiro argues that the difference across the countries is due to the different schools of interpretation of the religious text. in her article "Abortion Law in Muslim-majority Countries: An Overview of the Islamic Discourse with policy Implications," she analyzes the attitudes and policies on abortion in 47 Islamic countries from a more religious perspective and outlines the reasons why there is such great diversity. According to Shapiro, amongst the 47 Muslim Majority countries, 18 (38.3\%) allow abortion to save the mother's life, 9 (19.15\%) allow abortion for the mother's physical health, $8(17.02 \%)$ allow abortion for the mother's mental health, 2 (4.26\%) allow abortion in cases of fetal impairment, and 10 (21.28\%) allow abortion on demand (Shapiro 490).

Like Hessini, Shapiro also explains the significance of religion in the justice system and social values of Muslim majority countries. In her article, Shapiro mentions that "[i]f secular Western bioethics can be described as rights-based, with a strong emphasis on individual rights, Islamic bioethics is based on duties and obligations" (Shapiro 491). However, Shapiro also mentions some exceptions to this rule where countries have been motivated by secular factors to change abortion laws: "Instead, public health (on the basis of istislah) and economic development have been more persuasive. For example, Bowen (2003) deduces that abortion liberalization in Tunisia centered on economic development and Tunisia's concern to lower their birth rate" (Shapiro 491). Interestingly, Shapiro also states that some Muslim countries view abortion as more acceptable when the fetus is deformed or when there is a fetal impairment. This fact is important because, according to Hessini, consanguineous (cousin-to-cousin) marriage is the primary cause of fetal impairment and is practiced in more than $20 \%$ of marriages in Algeria and Morocco and more than 50\% in Jordan and Saudi Arabia (Hessini $81)$. 


\section{$2.3 \mathrm{~K}$ M Hedayat}

Unlike the previous two authors, K M Hedayat, P Shooshtarizadeh and M Raza analyze abortion through a very specific Shiite perspective in their article "Therapeutic abortion in Islam: contemporary views of Muslim Shiite scholars and effects of recent Iranian legislation." The main view of abortion among Shiite Muslims is that the fetus gains its soul after 4 months according to the Qur'an and thus abortion is not permitted after that point (Hedayat, Shooshtarizadeh, Raza 652). The main trend of abortion in Islamic countries is based on the different interpretation of the religious texts.

This article focuses mostly on Iran, which passed a law in 2003 that approved therapeutic abortion before 16 weeks of gestation under limited circumstances, including medical conditions related to fetal and maternal health. This law caused some stir in Muslim countries since it was passed in Iran, a country that many in this region look to as an example (Hedayat, Shooshtarizadeh, Raza 655). Although the laws and regulations in Iran are mostly based in religious and morality, evidence shows that, in writing this particular law, Iran's government also considered many social, economic, and medical factors, and took people's attitudes and social status into concern. As the authors state: "Islamic law has historically been flexible and sensitive to public needs and social realities," and "Iran is the first Islamic country in contemporary times that has attempted to combine principles of theocracy and religious law with the representative, parliamentary democracy" (Hedayat, Shooshtarizadeh, Raza 654-655). hHowever, despite the fact that more liberal laws have been set in Iran around abortion, many other Muslim countries have not been as considerate and realistic about the needs of the populous or the total cost of medical treatment on women who undergo illegal and unsafe abortions, and therefore have instated similar laws themselves.

Overall, this article shows how the Shiite leadership of Iran has become more tolerant toward abortion and has made an effort to consider social needs in its justice system, while maintaining the spirit of Islam's emphasis on respect for life, recognizing the emphasis of not making religion a burden on people. Iran is ruled by some of the most conservative Muslim clerics (Hessini 82) yet still passed the abortion laws that have set an example of access to reproductive services for Muslim countries overall.

\subsection{Donna Lee Bowen}

While some scholars have written about this topic by focusing on a specific country, others have approached it from an international perspective. For example, in Donna Lee Bowen's article "Abortion, Islam, and the 1994 Cairo Population Conference", she gives a more thorough and well-rounded explanation of the abortion debate among Islamic Scholars through the context of the 1994 Cairo International Population Conference. Bowen discusses the outcome of the discussions at this conference and draws conclusions from this discussion about Islamic abortion rights, reproduction rights, and even women rights more generally. The attitude towards abortion in Islam is, again, shaped primarily by religious beliefs, and yet this religious doctrine has restricted women's reproductive rights on a much larger scale than solely on the issue of abortion. The Islamic religion has a very conventional social view that values family as a more significant part of society than individuals. Bowen explains how this value system came into play at the Cairo International Population Conference: "Some Muslim delegations fought any attempt to substitute the term 'individual' for the family unit, because they feared this would promote premarital sex and homosexual unions" (Bowen 177). If Muslim countries did change their focus to individuals rather than families, scholars believe that this would encourage granting women the right to make decisions on their own behalf, and thus lower the importance of male domination and the submission of women (Bowen 177). Women do not control their own reproductive futures in these countries because all policies and decisions regarding abortion are made by male figures, either male politician or male physicians, a majority of Islamic countries require a husband's or parent's consent before giving a women an abortion (except in cases of medical danger), and in other countries male physicians are expected to decide the condition of the woman and decide whether or not an abortion should be granted (Bowen 175).

The policies in Islamic countries have been focusing on women and family issues. The majority of societal fears in Islam stem from the increase of sexual activity outside of marriage as Muslim sexual mores have begun to follow Western models; these fears underlie much of the current debate on abortion and have motivated Muslim governments to reject any attempts at granting women more independence in decisions concerning marriage, divorce, and inheritance (Bowen 179). Islamic culture expects women to stay at home, reproduce, and obey the men in the family, and this social norm deeply affects the decisions of Muslim policymakers (Bowen 179). Another cultural norm of Muslim society also affects its social value and policies, which is the valuing of large families as contributing to increasing the population and thus helping build a numerous, powerful society (Bowen 180), which is another reason why Islamic countries dislike abortion since they reduce family sizes. 
Abortion is thus a sensitive topic in Muslim society and regarded as more of a "Western problem." This has led to "the subject of abortion [becoming] a potent rallying cry against Western norms and mores that can be manipulated by political opposition in the Muslim states and by Islamist groups that are less educated in the subtleties of Islamic law than professors and legal scholars" (Bowen 180).

\section{Method}

In order to understand the portrayal countries' Muslim positions concerning abortion, I will analyze the descriptions of both the Islamic religion and the attitude of Muslims towards abortion displayed on the websites of 4 activist organizations, two of which position Islam as anti-abortion and two of which position Islam as open to abortion. I seek to answer the following question: How do anti-abortion and abortion rights groups deploy ideas about Islam in their activism regarding abortion?

\subsection{The Process}

I started off by searching for the keywords: "Muslim + abortion", "Islam + abortion", "Pro-choice Muslim" and "Pro-life Muslim" on Google. I got some useful results, but not as much information or the type of information that I'd expected. I was surprised to learn that the websites of many well-known and large-scale reproductive rights organizations and anti-abortion organizations (e.g. Planned Parenthood and Heartbeat International) contain very minimal information about Islam. I therefore started looking for information on smaller websites and found more information on abortion and Islam. These smaller websites included Muslims Pro-life, the Society for the Protection of Unborn Children, and the Religious Coalition for Reproductive Choice.

The remainder of this paper is divided into two sections; in the first section, I analyze the ways anti-abortion groups deploy their ideas on Islam and abortion; in the second section, I compare this with how abortion rights activists deploy their ideas on Islam and abortion.

\section{Research Process}

\subsection{Anti-abortion Websites}

\subsubsection{The Society of Unborn Children}

In order to understand how different reproductive justice and anti-abortion organizations deploy ideas about Islam, I looked on many of their websites to find relevant information. The first page that I will discuss is the Muslim section on the website of the Society of Unborn Children. This is an organization based in the United Kingdom, which was founded by Alan Smith and Elspeth Rhys-Williams in 1967; they introduce themselves as "the oldest pro-life campaigning and educational organization in the world." The first notable thing on this website is that, in the "Religious View" section of the "Abortion" category on the site, the Muslim section has the second shortest description (the "Hinduism" description has 13 fewer words), demonstrating a lack of any in-depth explanation of Islamic views on this issue. Here is what SPUC wrote on its website about abortion:

\section{Islam}

\section{Islam teaches that life begins at conception and is created by God. The unborn child has certain rights such as the right to care, protection and life. Abortion on any grounds is forbidden in the Islamic holy book Al'Quran. "Do not kill or take a human life which God has declared to be sacred." (Chapter 6,verse 151)}

(https://www.spuc.org.uk/abortion/religion)

SPUC uses one quote from the Qur'an to argue that "abortion on any ground is forbidden in the Islamic holy book Al'Quran." This statement makes no effort to cover the diverse attitudes of the Muslim population towards abortion. As mentioned previously, the views of abortion in Islam are actually more complex and centered around the timeline of the ensoulment of the fetus, which determines when the fetus becomes a human life, as well as the situation of the life of the mother. Abortion is also not mentioned at any point in the Holy Qur'an, which means that the SPUC statement "Abortion on any ground is forbidden in the Islamic holy book Al'Quran" is inaccurate. 
The SPUC titles this page "Religious Views" on abortion, so by summarizing the religious view on abortion of the Islamic religion with a single sentence from the Qur'an and relying heavily on one single interpretation of the Qur'an, this organization is either ignoring or ignorant of the diversity among the Muslim population in regards to this issue and the ongoing debates between Islamic scholars concerning abortion.

The "Religious View" page is not the only page on the SPUC website that includes information on Muslims. When you click on the subheading "Islam," a more detailed page appears which specifies the aims and activities of the SPUC Muslim Division.

\title{
SPUC Muslim Division
}

\begin{abstract}
SPUC's Muslim division was established in order to spread the pro-life message specifically to Muslims, and to support Muslim pro-lifers to be active in opposing abortion through their mosques and communities.
\end{abstract}

While SPUC is a non-religious organisation, we also recognise that it is important for individual pro-lifers who are religious to be able to reach out to their fellow believers and explain why the Islamic faith must include respect for human life at all stages of development.

The Muslim division is dedicated to encouraging the active participation of Muslims in the defence of sanctity of human life from conception till natural death, which is clearly expressed in the sacred texts of Islam. It maintains contact with leading figures in the British Muslim community and advises on the key issues affecting the sanctity of human life.

\section{Aims \& Activities}

The division works with and promotes solidarity with Muslims worldwide in their opposition to abortion, euthanasia, human cloning and population control. It watches for government participation in attempts to impose such policies that are contrary to the divine and humane values, which Islam shares with all major religions.

To learn more about the division and to find out how you could be involved, please contact the Muslim Division co-ordinator Dr. A. Majid Katme at muslims@spuc.org.uk

(https://www.spuc.org.uk/abortion/religion/muslims)

The first interesting sentence is in the second paragraph; it states that "the Islamic faith must include respect for human life at all stages of development." This statement is somewhat correct, since Islamic religion does include respect for human life; however, this sentence ignores the debate on whether or not the fetus is considered a life before 120 days, which is before its ensoulment. The next relevant sentence is in the third paragraph and describes the SPUC Muslim Division as "...encouraging the active participation of Muslims in the defense of the sanctity of human life from conception till natural death, which is clearly expressed in the sacred texts of Islam." This also shows the same ignorance of the Qur'an and the complex situation in Islamic countries. By using the words "must" and "defense" with the words "Islamic faith" and "Muslim", the editor of this webpage is trying to 
impart a sense of responsibility to Muslim readers, so that they will feel responsible as Muslims to support the stance of the SPUC on this issue.

The most compelling sentence on this page is right under the "Aims \& Activities" subheading: "The division works with and promotes solidarity with Muslims worldwide in their opposition to abortion..." I do not have any knowledge of what the situation concerning the other three subjects is in the Muslim society; but in terms of abortion, there can be no "solidarity with Muslims worldwide" since there is no single attitude on abortion among the Muslim population. Therefore, by using the term "solidarity" with the words "Muslims worldwide", the website is falsely generalizing the Muslim community and appealing to Muslim readers' sense of inclusion. The pride and sense of belonging that these words aim to inspire in Muslim readers could make them more likely to join the SPUC's political stance in abortion.

It is also worth noticing that the author of this page chooses to use only the word "Muslims" instead of using terms such as "pro-life Muslims" or "Muslims for life" (which would specify anti-abortion Muslims and exclude pro-choice Muslims), thus making it seem like all Muslims must take an opposing stance on abortion. SPUC represents Muslims as a united group of people that have the same opinions and attitudes. .

\title{
4.1.2 Pro-life Muslims
}

The next anti-abortion website I looked at was prolifemuslims.com. Surprisingly, this site was created by the coordinator of the Muslim Division of SPUC, Dr.A.Majid Katme, a Muslim pro-life activist. Although this website is made by a Muslim medical doctor who presumably is aware of the diversity in Islamic views on abortion, there are still attempts on the site to present a generalized view of Islam and to persuade people that Islam equals anti-abortion. For example, the website labels an anti-abortion protest as "This Humane Islamic Event." This phrase not only generalizes all Muslims, but also praises the Islamic religion as "humane" in order to gain approval from Muslim readers.

\section{MUSLIMS SHOULD JOIN THIS HUMANE ISLAMIC EVENT ON SATURDAY 28th APRIL}

\author{
In Britain ,about 600 healthy unborn children(boys and girls) are KILLED every day \\ through abortion! \\ About 200000 innocent lives are destroyed every year..and they have done nothing to \\ deserve that??? \\ Till now, about 7.5 million unborn children have been massacred in a barbaric way since \\ the Abortion Act came in 1967!
}

It is LEGAL to KILL your unborn baby up to 6 months pregnancy and up to birth(9 months) if the child is disabled or handicapped?

THIS IS VERY INHUMANE UNCIVILISED UNISLAMIC AND BARBARIC TOO! More, thousands of women are affected physically and mentally in their health following abortion?.

(http://www.prolifemuslims.com)

The website uses the word "Unislamic" to describe about abortion and encourages the creation of placards that say "ISLAM AGAINST ABORTION...MUSLIMS DEFENDING UNBORN CHILDREN..." This website, prolifemuslims.org, is thus trying to use the Islamic religion as a tool to attract and encourage more Muslims to take an anti-abortion stance; which nit does effectively because it establishes a personal connection with Muslim readers using religion.

It is reasonable that there is no mention of the debate among Muslim scholars on prolifemuslims.org since this website is created by a Pro-life Muslim activist; it is reasonable that Katme does not want any of the readers of the website to know that there is another side of this argument on abortion. This is also the reason why, on this website and on the SPUC website, there are so many mentions and quotes from the Qur'an without any explanations. The creators of those websites want to make readers think that Islamic holy texts are unambiguously pro-life and that there is absolutely no need for further explanation, both of which statements are false. 
I also realized that most of the anti-abortion websites that I browsed, including the websites of SPUC and Pro-Life Muslims, were related to either the United Kingdom or the United States. This could prove the point made by Leila Hessin that the anti-abortion movement in the middle east actually stems from western values rather than Muslim values and that anti-abortion activists from western countries are trying to involve themselves in abortion issues all over the world. These westerners might even be ignorant of the debates going on in Muslim countries and simply trying to impose their ideas and political stances without considering the local culture.

\subsection{Reproductive Rights Activists Websites}

\subsubsection{The Religious Coalition for Reproductive Choice}

The first pro-choice website I will focus on is that of the Religious Coalition for Reproductive Choice (RCRC, $\mathrm{http} / / / \mathrm{rcrc}$.org). According to this website, this organization "evolved from an underground network of ministers and rabbis called the Clergy Consultation Service (CCS), formed in 1967." This organization claims that "RCRC values and promotes religious liberty which upholds the human and constitutional rights of all people to exercise their conscience to make their own reproductive health decisions without shame and stigma." On this website, there is detailed information on multiple religions, including Islam, Christianity, Judaism, Hinduism, and Buddhism.

In contrast to the website of SPUC, The Muslim section on RCRC is very detailed; it contains 2,472 words, with a detailed analysis of the Qur'an and explanations of why the Islamic religion is not anti-abortion. RCRC gives a more well-rounded perspective on the Islamic religion's attitude towards abortion than either of the pro-life websites I analyzed. The author of this site (Khaleel Mohammed, a professor at San Diego State University), mentions "the Islamic discourse on abortion" and explains the concept of ensoulment and the 120 days argument.

\footnotetext{
Abortion

One of the main considerations in the Islamic discourse on abortion has to do with the concept of ensoulment. Strangely, the Qur'an has no concept of the neo-Platonic soul-body dualism that has come to be almost unanimously accepted as the Islamic weltan-schaaung. The renditions of certain Arabic words as "soul" in English translations of the Qur'an are due not to the actual meanings of the words themselves, but rather to creedal ideas. One such word is "nafs" - and it is related to the Hebrew "nephesh" — which basically means person or being.
}

(http://rcrc.org/muslim/)

He uses examples to prove that Islam is not necessarily anti-abortion and also writes about the argument on the other side of the Islamic abortion debate. As opposed to the previous two websites, RCRC uses explanations and examples to prove that Islam is not anti-abortion, appealing to the reader's logic and reasoning rather than the reader's emotions.

Since RCRC is based in Washington and SPUC is based in London, the two websites both represent the attitudes of activists around the issue of abortion in western countries and the general attitudes of the west towards the Muslim population.

\subsubsection{The Guttmacher Institute}

The second pro-choice website I chose to analyze is www.guttmacher.org. The Guttmacher institute "is a leading research and policy organization committed to advancing sexual and reproductive health and rights in the United States and globally."

Similar to RCRC, The Guttmacher Institute also uses details and proof to support their political stance. Since this website has a section focusing on Asia instead of solely on Muslim majority countries, there is less information specifically targeting Muslims. In the website's Asia section, much of the information (approximately 24\%) is presented as numbers.

Contrastingly to all three previous websites, the Guttmacher Institute website contains no mention of the Qur'an or the Islamic religion. The discussion on abortion on this webpage is purely based on statistics and data, which present a more objective perspective on abortion in the region of the Muslim majority countries. However, there is no specification of religion or culture in any of the statistics on this webpage. 


\section{UNSAFE ABORTION AND ITS CONSEQUENCES}

- Induced abortion is medically safe when WHO-recommended methods are used by trained persons, less safe when only one of those two criteria is met, and least safe when neither is met.

- As of 2010-2014, the majority (89\%) of abortions in Eastern Asia-which includes China-are safe. In Southern and Central Asia together, less than half of abortions are safe. ${ }^{3}$

- In 2012, approximately eight per 1,000 women of reproductive age in Asia (excluding Eastern Asia) were treated for complications from unsafe abortion. In all, about 4.6 million women in the region are treated for such complications each year. ${ }^{4}$

- In 2014 , at least $6 \%$ of all maternal deaths (or 5,400 deaths) in Asia were from unsafe abortion. ${ }^{5}$

- The most common complications from unsafe abortion are incomplete abortion, excessive blood loss and infection.

- Some women with untreated complications experience long-term health consequences, such as chronic pain, inflammation of the reproductive tract, pelvic inflammatory disease and infertility.

- Poor and rural women are the most likely to experience an unsafe abortion and severe complications thereof.

- Unsafe abortion has negative consequences beyond its immediate effects on individual women's health. Treating complications from unsafe abortion increases the economic burden on poor families and incurs considerable costs to already struggling public health systems.

- The extent to which medication abortion is used to induce abortions in Asia is not known; however, evidence indicates that sales of these drugs have increased in the region in the past decade. ${ }^{6}$

(https://www.guttmacher.org/geography/asia)

Despite the minimal information on Muslims in the Asia section of this website, I still found a very relevant article published by the Guttmacher Institute site called "Islam, Women and Family Planning: A Primer" by Heather D. Boonstra. This article discusses the subject of family planning methods (including contraception and abortion) in Muslim majority countries. Similarly to the RCRC website, this article also uses evidence to inform readers about the abortion issue in Muslim majority countries; however, the Guttmacher article uses more numbers and talks more about the social and economic factors in these countries, instead of focusing on the Qur'an only.

In his address to a joint session of Congress in the wake of the events of September 11, President George W. Bush went out of his way to acknowledge the vast majority of Muslims throughout the world whose faith is "good and peaceful" in contrast to the radical network of terrorists he described as "traitors of their own faith, trying, in effect, to hijack Islam itself." Behind Bush's remarks is a complexity of thinking about Islam that may not have been commonplace among Western observers. All too often Islam and its believers have been presented as one monolithic culture. Mention the plight of women in the Muslim world and the worst case scenarios come to mind: women strictly isolated within the home, subjected to public floggings and female genital cutting, forcibly given in marriage as a child and condemned to death for presumed adultery.

(https://www.guttmacher.org/geography/asia) 
For example, the article uses secular quotes this sentence about George W. Bush: "... of September 11, President George W. Bush ... acknowledge[d] the vast majority of Muslims throughout the world whose faith is 'good and peaceful' in contrast to the radical network of terrorists he described as 'traitors of their own faith, trying, in effect, to hijack Islam itself." The use of numbers in this article is also evident in sentences like, "In Egypt... some 216,000 women were hospitalized in 1996 for treatment of abortion-related complications, according to a study of post-abortion caseloads published in 1998 in International Family Planning Perspectives."

As opposed to the previous websites, this website is created by a research institute and thus does not include any evident generalizations of the Islamic religion nor the Muslim population. in the article, there is even a sentence that says "All too often Islam and its believers have been presented as one monolithic culture," suggesting that the author understands the different perspectives and diverse opinions among Muslim people. The majority of this website's information about Muslim majority countries is made up of numbers and objective analysis.

As a summary, anti-abortion activist websites mostly use citations from the Qur'an and uses Muslim's respect for their religion as a way to convince people of their political stance. There is a big possibility that anti-abortion activist websites generalize the Islamic religion in order to convince readers of their viewpoint, however it does not change the fact that anti-abortion activist groups portray Islam and Muslim people in a more narrow way, unconsciously categorizing Muslim people as monolithic and conservative, based on the religious nature of Muslim people. In contrast, Reproductive Justice organizations are clearly making deliberate attempts to seem more objective through their use of social science, statistics, and fact-based analysis in order to influence their readers and spread their beliefs. These pro-choice websites contextualize the Qur'an using evidence, put the content of the Qur'an into conversation with other ways of thinking, and draw from the diversity of Islamic scholars' views on abortions to justify their argument.

\section{Conclusion}

In this paper, I have sought to answer the question: How do anti-abortion and abortion rights groups deploy ideas about Islam in their activism regarding abortion? I have attempted to answer this question by analyzing what is said about Muslims and Islam on the websites of various reproductive justice and anti-abortion groups. My review of scholarly work on the issue of abortion in Muslim majority counties is also an important part of my paper because those articles have given me more knowledge on the topic of my research, thus enabling me to more objectively analyze the websites.

There are many questions that have occurred to me in this research process which I cannot answer in this paper but which could direct further research: Why do a significant amount of people worldwide have very monolithic and stereotypical impressions on the Islamic religion? How influential is religion to a country's justice system and social morals? Etc. These are very relevant research questions that I look forward to delving into further. These questions are too broad and in-depth, however, for a high school student to be able to answer them all in one paper. I hope that my research can have an impact and perhaps inspire further research into these questions.

\section{References}

"SPUC Muslim Division." Society for the Protection of Unborn Children. Retrieved from https://www.spuc.org.uk/abortion/religion/muslims

Boonstra, H. D. (n.d.). Islam, Women and Family Planning: A Primer. Guttmacher Institute. Retrieved from https://www.guttmacher.org/gpr/2001/12/islam-women-and-family-planning-primer

Bowen, D. L. (1997). International Journal of Middle East Studies.

Hedayat, K. M., Shooshtarizadeh, P., \& Raza, M. J. (2006). Med Ethics.

Hessini, L. (2007). Reproductive Health Matters.

Katme, A. M. (n.d.). Pro-life Muslims. Retrieved from http://www.prolifemuslims.com

Mohammed, K. (n.d.). Islam and Reproductive Choice. The Religious Coalition for Reproductive Choice.

Shapiro, G. K. (2013, June). Abortion law in Muslim-majority countries: an overview of the Islamic discourse with policy implications. Oxford University Press.

\section{Copyrights}

Copyright for this article is retained by the author(s), with first publication rights granted to the journal.

This is an open-access article distributed under the terms and conditions of the Creative Commons Attribution license (http://creativecommons.org/licenses/by/4.0/). 